\title{
Evaluation of Bile Salt Hydrolase Activity, Bile Salt Deconjugation Ability, Cholesterol Assimilation Ability and Antioxidative Activity of Lactobacillus Cultures
}

\author{
Dhvany Kinariwala ${ }^{1}$ and Subrota Hati ${ }^{2 *}$ \\ ${ }^{1}$ Department of Biochemistry, St. Xavier's College (Autonomous), Ahmedabad-380009, Gujarat, India \\ ${ }^{2}$ Department of Dairy Microbiology, Anand Agricultural University, Anand-388110, Gujarat, India \\ *Corresponding author: subrota_dt@yahoo.com
}

Received: 09-07-2019

Revised: $14-10-2019$

Accepted: 28-11-2019

\begin{abstract}
Probiotic potential of three cultures of Lactobacillus namely L.fermentum (M2), L.fermentum (M7) and L.paracasei (M11) were carried out by performing various in vitro tests such as bile salt hydrolase activity, bile salt deconjugation ability, cholesterol assimilation ability and antioxidative activity (ABTS method). M7 and M11 showed positive bile salt hydrolase activity. M2, M7 and M11 have the ability to deconjugate bile salt and M11 culture exhibited for the highest deconjugation of bile salt $(616.25 \mu \mathrm{g} / \mathrm{mL})$. These three cultures were able to survive in MRS broth containing $0.2 \%$ sodium thioglycolate and $0.3 \%$ sodium taurocholate (conjugated bile salt). Antioxidant activity was also evaluated among these Lactobacillus cultures and found in the range of $46.55 \%$ to $78.66 \%$. But, these three cultures were very poor to assimilate the cholesterol. This study indicated that L. paracasei (M11)was more potent than other cultures.
\end{abstract}

Keywords: Lactobacillus, Bile salt hydrolase, Bile deconjugation ability, Cholesterol assimilation, Antioxidative activity

Many studies show the usefulness of lactic acid bacteria (LAB) as probiotics for human and animals (Lee and Salminen, 1995; Tannock, 1997; Brashears et al. 2003; Hamilton-Miller, 2003). It has been claimed that lots of commercial products or food containing LAB are healthy (Rolfe, 2000; Sakamoto et al. 2001; Sanders, 2003). Some LAB items have been demonstrated to be valuable as aides to keep human from gastrointestinal issue and from intense enteritis (Coconnier et al. 2000; Armuzzi et al. 2001). Probiotics have been used in various fermented foods for a long time. There are many commercial products available in the markets all over the world which contains LAB. These LAB products are available in liquid form, such as yogurt, and solid form, such as powder, granule and tablet. Most of the LAB cultures are used in combination which means product contains two or more LAB cultures. These cultures include Lactobacillus thermophilus, Streptococcus bulgaricus, Lactobacillus acidophilus, Lactobacillus casei and Bifidobacterium longum, etc (Analie and Viljoen, 2001). The genus Lactobacillus is the biggest of the genera remembered for lactic corrosive microorganisms with more than hundred species perceived at present. The genus Lactobacillus is heterogeneous containing species with considerable contrasts in their phenotypic, biochemical, physiological and genotypic attributes. The food and feed industry focus to utilize the lactobacilli for the fermentation of vegetables, silage, sourdough bread, and other milk and meat items, albeit a few species additionally found to ruin the food sources (Stiles and Holzapfel, 
1997). LAB species are generally recognized as safe (GRAS) and European Food Safety Authority (EFSA) has stated that several LAB speciesare Qualified Presumption of Safety (QPS). Aside from their role in food fermentations and preservation, there is a developing intrigue for $\mathrm{LAB}$ regarding health benefits and other medicinal applications. Some species of $\mathrm{LAB}$ have the potential to improve human health by various means such as strengthening the body's natural defense to fend off undesirable microorganisms, modulating the immune system by enhancing host's immune response (Reid et al. 2003), binding and removal of carcinogens, production of antimutagenic compounds and improving overall intestinal and urinary-genital health and so on (Parvez et al. 2006). Proof from in vitro systems, animal models and human clinical examinations propose that $\mathrm{LAB}$ work as immunomodulators and can improve both explicit and vague insusceptible reactions (Ouwehand et al. 2002; O'Flaherty and Klaenhammer, 2010) legitimizing their utilization as wellbeing advancing enhancements or probiotics both for people and animals. Utilization of food containing probiotic microscopic organisms influence the gastrointestinal tract (GIT) as they develop and increase in GIT to applies different wellbeing advancing activities. Main purpose of this study is to check safety and efficacy of Lactobacillus cultures.

\section{MATERIALS AND METHODS}

The present study was planned to check probiotic potential of lactic acid bacterial isolates by in vitro tests.

\section{Collection of LAB isolates and their maintenance}

The LAB cultures used in the present study were obtained from the Culture Collection of Dairy
Microbiology Department, SMC College of Dairy Science, Anand (Table 1). The LAB cultures were propagated in sterilized reconstituted skim milk. The transfer was given every week during the study. Before use in the study, they were activated by propagation in MRS broth by daily transfers.

\section{Evaluation of probiotic potential of LAB isolates by in vitro tests}

Three potent Lactobacillus cultures i.eL. fermentum (M2), L. fermentum (M7) and L. paracasei (M11) were taken for evaluating their probiotic potential as follows.

\section{Bile salt hydrolase activity}

It was performed by plate assay method (Jayashree et al. 2014) which is found ubiquitously in fermented milk products. Bile salt hydrolase (BSH with some modifications. For the well assay, wells were prepared using a gel puncture on MRS agar plates with $0.3 \%$ bile salts and $0.2 \%$ sodium thioglycolate. In each well, $150 \mu \mathrm{L}$ of supernatant of activated cultures were added and incubated at $6 \pm 2^{\circ} \mathrm{C}$ for $3 \mathrm{~h}$. The bile acid precipitates around the colonies (opaque halo) or the formation of opaque granular white colonies with silvery shine was considered as BSH activity.

\section{Bile deconjugation ability}

Bile deconjugation ability of LAB cultures were tested by the method of Irvin et al. (1994) as modified by Walker and Gilliland (1993) and Ashar and Prajapati (1998). MRS broth medium containing $0.2 \%$ sodium thioglycollate to which conjugated bile salt (sodium taurocholate) was separately added at $0.3 \%$ rate, was used to test the same. Active test cultures were inoculated at the rate of $2 \%$ into $20 \mathrm{~mL}$ MRS broth tubes. An uninoculated broth tubes were also kept

Table 1: Gene accession number and isolation source of LAB isolates

\begin{tabular}{|c|c|c|c|c|c|}
\hline $\begin{array}{l}\text { Sl. } \\
\text { No. }\end{array}$ & Culture Name & Source of Isolation & Selective Media & Growth Conditions & $\begin{array}{l}\text { Gene bank } \\
\text { Accession no. }\end{array}$ \\
\hline 1 & Lb. fermentum (M2) & Fermented rice beve & MRS Agar & $37^{\circ} \mathrm{C}$ for $24 \mathrm{~h}$ & MF951094 \\
\hline 2 & Lb. fermentum (M7) & Fermented rice beve & MRS Agar & $37^{\circ} \mathrm{C}$ for $24 \mathrm{~h}$ & MF951099 \\
\hline 3 & Lb. paracasei (M11) & Fermented rice beve & MRS Agar & $37^{\circ} \mathrm{C}$ for $24 \mathrm{~h}$ & MG027695 \\
\hline
\end{tabular}


along with the test. The tubes were incubated at $37^{\circ} \mathrm{C}$ under reduced $\mathrm{O}_{2}$ atmosphere in a gas pack jar for 24 h. An anaerobic indicator tablet was kept in gas pack jar to indicate reduced condition.

\section{Extraction of free cholic acid}

After incubation, the spent broth was adjusted to $\mathrm{pH}$ 7 using $1[\mathrm{~N}] \mathrm{NaOH}$. Then volume was made to 25 $\mathrm{mL}$ with distilled water. The cells were removed by centrifugation at $10,000 \mathrm{rpm}$ for $15 \mathrm{~min}$ at $4^{\circ} \mathrm{C}$. Fifteen $\mathrm{mL}$ of the resultant supernatant fluid was adjusted to pH 1 with 10 [N] HCL and the volume was increased to $25 \mathrm{~mL}$ with distilled water. Three $\mathrm{mL}$ of this fluid broth was taken as sample and $9 \mathrm{~mL}$ of ethyl acetate was added. The contents were thoroughly mixed on cyclomixer and the tubes were kept undisturbed for some time to allow phase separation. Thereafter, $3 \mathrm{~mL}$ of ethyl acetate layer was taken in $18 \mathrm{~mm}$ diameter test tubes and was evaporated to dryness in a water bath at $60^{\circ} \mathrm{C}$.

\section{Estimation of free cholic acid}

One $\mathrm{mL}$ of $0.1[\mathrm{~N}] \mathrm{NaOH}$ was added to the tubes to dissolve the residue followed by the addition of $6 \mathrm{~mL}$ of [16] $\mathrm{N} \mathrm{H}_{2} \mathrm{SO}_{4}$ and $1 \mathrm{~mL}$ of $1 \%$ furfuraldehyde. The tubes were heated for $15 \mathrm{~min}$ in a water bath at $65^{\circ} \mathrm{C}$ followed by subsequent cooling to room temperature. Five $\mathrm{mL}$ of glacial acetic acid was added finally to stop the colour development. Then the tubes were measured for the absorbance at $660 \mathrm{~nm}$ wavelength against a reagent blank using Systronic PC based double beam Spectrophotometer, 2206. Standard curve for free bile acid (cholic acid) was prepared by taking 100, 200, 400, 600, 800 and $1000 \mu \mathrm{g}$ of cholic acid. Cholic acid used for preparation of standard curve was dissolved in $0.1[\mathrm{~N}] \mathrm{NaOH}$ and then further diluted with distilled water as per the concentration desired per $\mathrm{mL}$ and following the above-mentioned procedure for estimation. The free cholic acid content in the uninoculated as well as inoculated tubes was obtained by interpolation from the standard curve. The difference of cholic acid in test and blank was calculated individually for each strain and this value was expressed as $\mu \mathrm{g} / \mathrm{mL}$ of free cholic acid released in the medium.

\section{Cholesterol assimilation ability}

The procedure of Gilliland and Walker (1990) adopted by Ashar and Prajapati (1998) was followed for the study of cholesterol assimilation activity by the culture. Fifty $\mu \mathrm{g} / \mathrm{mL}$ of cholesterol was aseptically added into $10 \mathrm{~mL}$ of MRS broth base containing $0.2 \%$ sodium thioglycollate and $0.3 \%$ sodium taurocholate. To this broth media tubes, $24 \mathrm{~h}$ active test strain of $\mathrm{LAB}$ was inoculated at the rate of $2 \%$. The tubes were incubated anaerobically under reduced $\mathrm{O}_{2}$ conditions in a gas pack jar at $37^{\circ} \mathrm{C}$ up to $24 \mathrm{~h}$. Thereafter, the content of the tubes was centrifuged at 10,000 rpm for $10 \mathrm{~min}$ at $4^{\circ} \mathrm{C}$ (Eppendorf Centrifuge, US). Supernatant broth obtained thus was treated as sample and $0.5 \mathrm{~mL}$ of the same was transferred into a clean test tube.

\section{Extraction}

To the above sample, $3 \mathrm{~mL}$ of $95 \%$ ethanol followed by $2 \mathrm{~mL}$ of $50 \% \mathrm{KOH}$ were added to the tubes and the contents were mixed thoroughly on a cyclomixer. Thereafter the tubes were heated for $10 \mathrm{~min}$ in a water bath maintained at $60^{\circ} \mathrm{C}$ and cooled subsequently. Further, $5 \mathrm{~mL}$ of hexane was added, and the tubes were mixed thoroughly. Then, $3 \mathrm{~mL}$ of distilled water was added, and the mixing was repeated. To permit phase separation, the tubes were allowed to stand for $15 \mathrm{~min}$ at room temperature. Thereafter, $2.5 \mathrm{~mL}$ hexane layer was transferred into clean test tubes. The hexane was evaporated from the tubes by heating them at $60^{\circ} \mathrm{C}$ using hot water bath for an overnight period.

\section{Estimation}

The method of Rudel and Morris (1973) using O-phthalaldehyde (OPA) was followed. In this method, $4 \mathrm{~mL}$ of OPA reagent (50 mg OPA per liter of glacial acetic acid) was added in above dried extracts and the tubes were allowed to stand at room temperature for $10 \mathrm{~min}$. Then, $2 \mathrm{~mL}$ of concentrated sulphuric acid was added slowly from the side of the test tube and the contents mixed thoroughly on cyclomixer. The tubes were allowed to stand at room temperature for further $10 \mathrm{~min}$. Then, the 
test absorbance was read against blank at $550 \mathrm{~nm}$ wavelength on Systronic PC based double beam Spectrophotometer, 2206. Results were recorded in terms of percentage reduction in cholesterol in the test supernatant broth as compared to that in the uninoculated blank supernatant broth.

$\%$ cholesterol removal from media $=\frac{c_{0}-c_{1}}{c_{0}} \times 100$

Where,

$\mathrm{C}_{0}: \mathrm{OD}_{550}$ of MRS broth supernatant containing no culture

$\mathrm{C}_{1}: \mathrm{OD}_{550}$ of MRS broth supernatant containing culture

\section{Antioxidative activity}

Free radical scavenging activity was determined by the ABTS method followed by Hati et al. (2018) with slight modifications.

The ABTS working solution was prepared by mixing $88 \mu \mathrm{L}$ of $140 \mathrm{mM}$ potassium persulphate with $5 \mathrm{~mL}$ of $7 \mathrm{mM}$ ABTS stock solution and incubating overnight in dark bottles for generation of radicals. An aliquot of $5 \mathrm{~mL}$ of this solution was added to $150 \mathrm{~mL}$ PBS to adjust the absorbance at $734 \mathrm{~nm}$ to $0.7 \pm 0.02$. Active culture supernatant was collected by centrifuging at $10,000 \mathrm{rpm}$ for $10 \mathrm{~min}$ at $4^{\circ} \mathrm{C}$ (Eppendorf Centrifuge, US). $200 \mu \mathrm{L}$ of cell supernatant was added to $2.0 \mathrm{~mL}$ ABTS in PBS solution and absorbance was measured at $734 \mathrm{~nm}$. As a blank double distilled water was used. ABTS activity was calculated as follow:

Antioxidant $(\%)=\frac{\text { Control }- \text { Sample }}{\text { Control }} \times 100$

\section{Statistical methods}

All the data were subjected to statistical analysis using one factor and two factor Completely Randomized Design (CRD) as per the requirement. The significance was tested on basis of comparison between calculated value and Table F-value. Standard error of mean value, co-efficient of variance (C.V.) and critical difference (C.D.) were determined. The values for microbial counts were log transformed before analysis.

\section{RESULTS AND DISCUSSION}

\section{Evaluation of Lactobacillus cultures for probiotic potential}

Probiotic potential of three Lactobacillus cultures (M2, M7 and M11) were carried out by performing a battery of in vitro tests i.e. bile salt hydrolase activity, bile deconjugation ability, cholesterol assimilation ability and antioxidative activity.

\section{Evaluation of Lactobacillus cultures for bile salt} hydrolase activity (BSH)

Lactobacillus cultures M2, M7 and M11 were evaluated for BSH activity following the method of Jayashree $e t$ al. (2014). It was observed that M7 showed positive activity up to $3 \mathrm{~h}$ of incubation followed by M11 whether M2 did not show any significant bile hydrolyzation (Fig. 1).

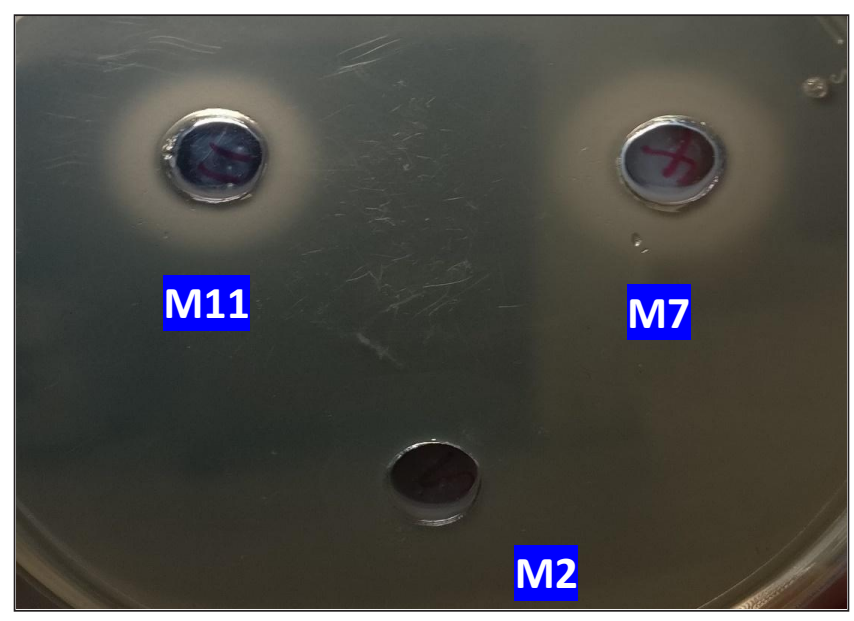

Fig. 1: BSH activity of Lactobacillus cultures

Certain probiotic strains of lactic acid bacteria have capacity to enzymatically deconjugate bile acids through bile salt hydrolase catalysis. Partial absorbance of the deconjugated bile acids are done through the intestinal cell wall while remaining deconjugated bile acid will be discharged out. The utilization of cholesterol to blend new bile would prompt a diminished convergence of cholesterol in blood because cholesterol is the precursor of bile acids (Lye et al. 2009). Tanaka et al. (2000) had observed that almost all bifidobacterium species and strains have 
bile salt hydrolase activity, while this action must be found in chosen species of lactobacilli. Argyri et al. (2013) had reported that Lactobacillus plantarum and Lactobacillus pentosus (strains isolated from fermented olives)exhibit partial bile salt hydrolase activity. Commercial probiotic strains and culture collection strains were studied for screening of BSH activity by using TLC method and plate assay. Among all the 59 Lactobacillus strains, 15 strains were shown to be BSH positive by TLC method and 8 strains of them by plate assay. Most of the BSH positive strains were isolated from feces (Sedláčková et al. 2015).

Evaluation of Lactobacillus cultures for bile salt deconjugation ability

Bile salt deconjugation was determined by the amount of cholic acid released. Free cholic acid released from sodium taurocholate by cultures is presented in Table 2 . The values were calculated from the standard curve prepared using various concentration of cholic acid.

Table 2: Amount of free cholic acid released by Lactobacillus cultures

\begin{tabular}{lll}
\hline $\begin{array}{l}\text { Lactobacillus } \\
\text { cultures }\end{array}$ & $\begin{array}{l}\text { Free cholic acid } \\
(\mu \mathrm{g} / \mathrm{mL})\end{array}$ & $\begin{array}{l}\text { Free cholic acid } \\
(\mu \mathrm{g} / \mathrm{mL})\end{array}$ \\
\hline Control & 532.875 & - \\
M2 & 922.875 & 390 \\
M7 & 679.125 & 146.25 \\
M11 & 1125.125 & 616.25 \\
\hline
\end{tabular}

M11 exhibited highest bile deconjugation ability (616.25 $\mu \mathrm{g} / \mathrm{mL}$ cholic acid from sodium taurocholate) followed by M2 (390 $\mu \mathrm{g} / \mathrm{mL}$ cholic acid) and M7 (146.25 $\mathrm{\mu g} / \mathrm{mL}$ cholic acid). Results showed that control has also some capability to deconjugate bile salts.

Begley et al. (2008) had said that deconjugated bile salts are just somewhat reabsorbed in the intestinal lumen, which brings about discharge of free bile salts into feces; accordingly, cholesterol is utilized for de-novo synthesis of bile acids, in this manner diminishing serum cholesterol level. Free bile salts likewise wastefully solubilize cholesterol (lipids) in digestion tracts along these lines further reducing cholesterol absorption. Sontakke (1992) had performed bile deconjugation ability test for different strains of lactobacilli and he had observed that only Lactobacillus acidophilus $(\mathrm{CH})$ was able to deconjugate sodium taurocholate and sodium glycocholate. Ashar and Prajapati (1998) had checked bile deconjugation ability of different strains of acidophilus namely $\mathrm{Lb}$. acidophilus $\mathrm{H} 3, \mathrm{Lb}$. acidophilus $\mathrm{C} 2, \mathrm{Lb}$. acidophilus V3 and $L b$. acidophilus I4. Among them H3 released maximum amount $(443 \mu \mathrm{g} / \mathrm{ml})$ of cholic acid from sodium taurocholate, followed by C2 $(422 \mu \mathrm{g} / \mathrm{ml}), \mathrm{V} 3$ $(389 \mu \mathrm{g} / \mathrm{ml})$ and $\mathrm{I} 4(332 \mu \mathrm{g} / \mathrm{ml})$ after $24 \mathrm{~h}$ of growth at $37^{\circ} \mathrm{C}$. In our findings, M2 ( $\mathrm{b}$. fermentum)has capacity to deconjugate bile acids about $390 \mu \mathrm{g} / \mathrm{mL}$ which value is almost nearest with V3 $(389 \mu \mathrm{g} / \mathrm{mL})$.

\section{Evaluation of Lactobacillus cultures for cholesterol assimilation ability}

Cholesterol assimilation ability of Lactobacillus cultures after $24 \mathrm{~h}$ anaerobic incubation in MRS broth was determined. The results of cholesterol assimilation by cultures of lactobacilli after $24 \mathrm{~h}$ incubation under reduced $\mathrm{O}_{2}$ tension maintained in gas pack jar are presented in Fig. 2 and it was found that these cultures [M2 (3.15\%), M7 (1.05\%) and M11 (5.11\%)] have very low ability to assimilate cholesterol.

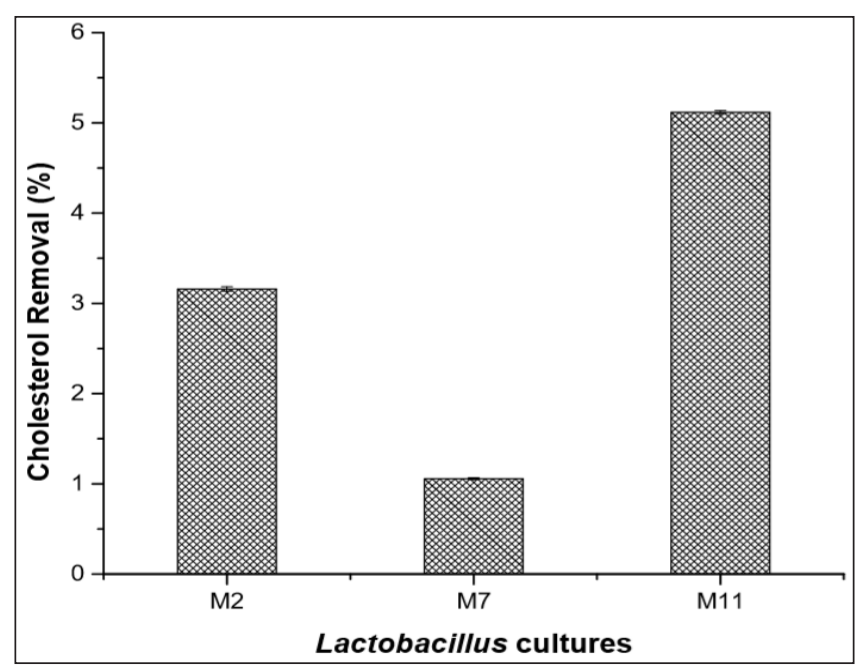

Fig. 2: Cholesterol assimilation ability of Lactobacillus cultures 
Several theories of how probiotics remove host cholesterol have been put forward. They are mainly: (1) Assimilation (2) Coprecipitation (3) Adsorption and incorporation4) Reduction of the cholesterol absorption by host (Li 2012). Ashar and Prajapati (1998) had performed cholesterol assimilation ability test for four strains of Lactobacillus acidophilus (V3, I4, H3 and C2). They observed that strains have ability to reduce cholesterol ranged from 3.2 to 25.3 percent within $48 \mathrm{~h}$ by in vitro study.

\section{Evaluation of Lactobacillus cultures for antioxidative} activity

The antioxidant activity was measured in terms of free radical scavenging activity (RSA) using ABTS assay method and results were expressed in terms of percentage $(\%)$ of inhibition. Absorbance was measured at $734 \mathrm{~nm}$ for $6 \mathrm{~min} 20 \mathrm{sec}$ at every $10 \mathrm{sec}$. The results obtained for 3 Lactobacillus cultures by ABTS (2, 2'-Azinobis (3-ethylene benzothiazoline) 6-Sulphonicacid) assay is and the trend of inhibition rate of selected Lactobacillus cultures has shown in Fig. 3.

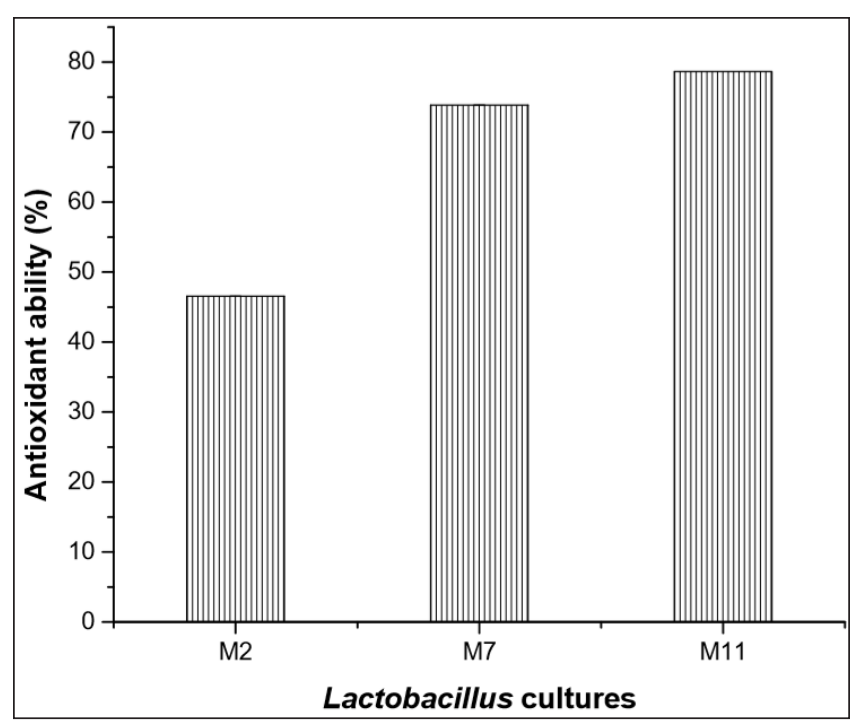

Fig. 3: Antioxidative activity of Lactobacillus cultures

M11 culture had higher antioxidant activities (78.66\%) but according to statistical analysis, there is no significant difference between M7 and M11. Only $46.55 \%$ inhibition of oxidation process was observed by M2 culture.

According to the free radical theory of aging (Muller et al. 2007), the interruption of the sensitive balance between generation of reactive oxygen species (ROS) and antioxidant scavenging systems with increasing age could lead to a shift to an oxidative cellular milieu, and eventually lead to serious health problems such as diabetes and Alzheimer's disease. Therefore, it is necessary to protect the human body from free radicals and retard the progress of many chronic diseases (Bellino, 2006; Getoff, 2007). Some LAB own antioxidant activity and can reduce the risk of accumulation of ROS during ingestion of food (Kaizu et al. 1993).

Nearly alllactic acid bacteria have system to survive with oxygen radicals. $\mathrm{LAB}$ was noticed to corrupt the superoxide anion and hydrogen peroxide in vitro (Kullisaar et al. 2002). The antioxidant activity of probiotic cultures viz. S. thermophilus MTCC 5460 and $L b$. helveticus MTCC 5463, was determined by ABTS method. It was observed that antioxidative activity of $L b$. helveticus 5463, S. thermophilus MTCC 5460 and combination of both the cultures was $0.47 \%$, $3.01 \%$ and $5.46 \%$ respectively (Shah, 2011).

\section{CONCLUSION}

Based on the above results, for bile salt hydrolase activity, M7 showed maximum zone around the well (in agar plate) than M11. These three Lactobacillus cultures M2, M7 and M11 were able to survive in presence of bile and showed their ability to hydrolase (except M2) and deconjugate. But they are poor to assimilate cholesterol. M7 and M11 culture showed maximum antioxidant activities (78.66\%). Further, health claims for particular Lactobacillus cultures need to be validated on conducting clinical trials on human subjects.

\section{ACKNOWLEDGEMENTS}

The authors kindly acknowledge the funding support received from the Department of Biotechnology, New Delhi, Government of India (Agri/2015/02) under the Twining project-2015. 


\section{REFERENCES}

Argyri, A.A., Zoumpopoulou, G., Karatzas, K.A.G., Tsakalidou, E., Nychas, G.J.E., Panagou, E.Z. and Tassou, C.C. 2013. Selection of potential probiotic lactic acid bacteria from fermented olives by in vitro tests. Food Microbiology, 33(2): 282-291.

Armuzzi, A., Cremonini, F., Bartolozzi, F., Canducci, F., Candelli, M., Ojetti, V. and Gasbarrini, G. 2001. The effect of oral administration of Lactobacillus GG on antibioticassociated gastrointestinal side-effects during Helicobacter pylori eradication therapy. Alimentary Pharmacology and Therapeutics, 15(2): 163-169.

Ashar, M.N. and Prajapati, J.B. 1998. Bile tolerance, bile deconjugation and cholesterol reducing properties of dietary lactobacilli. Indian Journal of Microbiology, 38(3): 145-148.

Begley, T.P., Chatterjee, A., Hanes, J.W., Hazra, A. and Ealick, S.E. 2008. Cofactor biosynthesis-still yielding fascinating new biological chemistry. Current Opinion in Chemical Biology, 12(2): 118-125.

Bellino, F.L. 2006. Advances in endocrinology of aging research, 2005-2006. Experimental Gerontology, 41(12): 12281233.

Brashears, M.M., Jaroni, D. and Trimble, J. 2003. Isolation, selection, and characterization of lactic acid bacteria for a competitive exclusion product to reduce shedding of Escherichia coli O157: H7 in cattle. Journal of Food Protection, 66(3): 355-363.

Coconnier, M.H., Liévin, V., Lorrot, M. and Servin, A.L. 2000. Antagonistic activity of Lactobacillus acidophilus LB against intracellular Salmonella enterica serovar Typhimurium infecting human enterocyte-like Caco-2/TC-7 cells. Applied and Environmental Microbiology, 66(3): 1152-1157.

Getoff, N. 2007. Anti-aging and aging factors in life. The role of free radicals. Radiation Physics and Chemistry, 76(10): 1577-1586.

Gilliland, S.E. and Walker, D.K. 1990. Factors to consider when selecting a culture of Lactobacillus acidophilus as a dietary adjunct to produce a hypocholesterolemic effect in humans. Journal of Dairy Science, 73(4): 905-911.

Hamilton-Miller, J.M.T. 2003. The role of probiotics in the treatment and prevention of Helicobacter pylori infection. International Journal of Antimicrobial Agents, 22(4): 360-366

Hati, S., Patel, N. and Mandal, S. 2018. Comparative growth behaviour and biofunctionality of lactic acid bacteria during fermentation of soy milk and bovine milk. Probiotics and Antimicrobial Proteins, 10(2): 277-283.

Irvin, J.L., Johnston, C.G. and Kopala, J. 1944. A photometric method for the determination of cholates in bile and blood. Journal of Biological Chemistry, 153(2): 439-457.
Jayashree, S., Pooja, S., Pushpanathan, M., Rajendhran, J. and Gunasekaran, P. 2014. Identification and characterization of bile salt hydrolase genes from the genome of Lactobacillus fermentum MTCC 8711. Applied Biochemistry and Biotechnology, 174(2): 855-866.

Kaizu, H., Sasaki, M., Nakajima, H. and Suzuki, Y. 1993. Effect of antioxidative lactic acid bacteria on rats fed a diet deficient in vitamin E. Journal of Dairy Science, 76(9): 24932499.

Kullisaar, T., Zilmer, M., Mikelsaar, M., Vihalemm, T., Annuk, H., Kairane, C. and Kilk, A. 2002. Two antioxidative lactobacilli strains as promising probiotics. International Journal of Food Microbiology, 72(3): 215-224.

Lee, Y. K. and Salminen, S. 1995. The coming of age of probiotics. Trends in Food Science and Technology, 6(7): 241245.

Li, G. 2012. Intestinal probiotics: interactions with bile salts and reduction of cholesterol. Procedia Environmental Sciences, 12: 1180-1186.

Lourens-Hattingh, A. and Viljoen, B.C. 2001. Yogurt as probiotic carrier food. International Dairy Journal, 11(1-2): $1-17$.

Lye, H.S., Kuan, C.Y., Ewe, J.A., Fung, W.Y. and Liong, M.T. 2009. The improvement of hypertension by probiotics: effects on cholesterol, diabetes, renin, and phytoestrogens. International Journal of Molecular Sciences, 10(9): 3755-3775.

Muller, F.L., Lustgarten, M.S., Jang, Y., Richardson, A. and Van Remmen, H. 2007. Trends in oxidative aging theories. Free Radical Biology and Medicine, 43(4): 477-503.

O'Flaherty, S. and Klaenhammer, T.R. 2010. The role and potential of probiotic bacteria in the gut, and the communication between gut microflora and gut/ host. International Dairy Journal, 20(4): 262-268.

Ouwehand, A.C., Salminen, S. and Isolauri, E. 2002. Probiotics: an overview of beneficial effects. In Lactic Acid Bacteria: Genetics, Metabolism and Applications, pp. 279-289.

Parvez, S., Malik, K.A., Ah Kang, S. and Kim, H.Y. 2006. Probiotics and their fermented food products are beneficial for health. Journal of Applied Microbiology, 100(6): 1171-

Reid, G., Jass, J., Sebulsky, M.T. and McCormick, J.K. 2003. Potential uses of probiotics in clinical practice. Clinical Microbiology Reviews, 16(4): 658-672.

Rolfe, R.D. 2000. The role of probiotic cultures in the control of gastrointestinal health. The Journal of Nutrition, 130(2): 396S-402S.

Rudel, L.L. and Morris, M.D. 1973. Determination of cholesterol using o-phthalaldehyde. Journal of Lipid Research, 14(3): 364366.

Sakamoto, I., Igarashi, M., Kimura, K., Takagi, A., Miwa, T. and Koga, Y. 2001. Suppressive effect of Lactobacillus gasseri OLL 2716 (LG21) on Helicobacter pylori infection 
in humans. Journal of Antimicrobial Chemotherapy, 47(5): 709710 .

Sanders, M.E. 2003. Probiotics: considerations for human health. Nutrition Reviews, 61(3): 91-99.

Shah, C.H. 2011. Antioxidative activity of selected symbiotic fermented dairy products. M. Sc. Thesis submitted to Anand Agricultural University, Anand, Gujarat, India.

Sontakke, A.T. 1992. Beneficial activities of selected human strains of Lactobacilli in milk for its use as dietary adjunct. $\mathrm{PhD}$ Thesis submitted to Gujarat Agricultural University, Anand.

Stiles, M.E. and Holzapfel, W.H. 1997. Lactic acid bacteria of foods and their current taxonomy. International Journal of Food Microbiology, 36(1): 1-29.
Tanaka, H., Hashiba, H., Kok, J. and Mierau, I. 2000. Bile salt hydrolase of Bifidobacterium longum-biochemical and genetic characterization. Applied and Environmental Microbiology, 66(6): 2502-2512.

Tannock, G.W. 1997. Probiotic properties of lactic-acid bacteria: plenty of scope for fundamental $\mathrm{R}$ and $\mathrm{D}$. Trends in Biotechnology, 15(7): 270-274.

Sedláčková, P., Horáčková, Š., Shi, T., Kosova, M. and Plocková, M. 2015. Two different methods for screening of bile salt hydrolase activity in Lactobacillus strains. Czech Journal of Food Sciences, 33(1): 13-18.

Walker, D.K. and Gilliland, S.E. 1993. Relationships among bile tolerance, bile salt deconjugation, and assimilation of cholesterol by Lactobacillus acidophilus. Journal of Dairy Science, 76(4): 956-961. 